\title{
Digital Amnesia: are we headed towards another amnesia
}

\author{
Pragya Lodha \\ Research Assistant and Clinical Psychologist, Desousa Foundation, Mumbai \\ Corresponding author: Pragya Lodha \\ Email - pragya6lodha@gmail.com
}

\begin{abstract}
Digital amnesia is a concept that existed since 2007 and has addressed this phenomenon as a constant threat to human memory arising out of excessive digital gadget use. The following review paper looks at the construct of digital amnesia from its inception to its current conceptualization. The paper also reviews the phenomenon named the Google effect and the seminal findings from studies of Kapersky Laboratory conducted in India and abroad. The process of how digital amnesia is caused is addressed and preventive measures for the same are suggested.
\end{abstract}

Keywords: Digital amnesia, amnesia, digital use, google effect.

(Paper received $-20^{\text {th }}$ January 2019, Peer review completed $-5^{\text {th }}$ February 2019)

(Accepted $-8^{\text {th }}$ February 2019)

"Erosion of institutional memory in a digitally documented world is a real, and increasingly urgent, threat."

Tim Cook

Digital Amnesia is a concept that has existed since 2007, first introduced in the study conducted at Dublin [1] that addressed the phenomenon as a rising threat to the human memory as a consequence to overuse of technology. The term was also referred to as technology induced memory atrophy. Another synonymous term is 'Digital Dementia', coined by a German neuroscientist Manfred Spitzer [2], used to describe how overuse of digital technology is resulting in the breakdown of cognitive abilities in a way that is more commonly seen in people who have suffered a head injury or psychiatric illness. The history of digital amnesia as a phenomenon also recognises the work done by three major universities - Harvard University, University of Columbia and the University of Wisconsin. Researchers from these universities were interested to study the effect of technology on youth and their research resulted in coining the term 'Google Effect' that was described as the tendency to forget information that can be easily found online (via search engines like 'Google') [3]. Digital amnesia and Google effect are used in an exchangeable manner; however, digital amnesia is referred to as the tendency to forget information that one has stored on a digital device. The term was officially coined by Kaspersky Laboratory [4], a cyber-security firm based in Moscow, Russia. Both of these phenomena are similar, in that one forgets, either intentionally or unintentionally, information that is digitally available. The prime reason for this forgetting is that the source of the information is better remembered than the information itself. Thus, every time one wants to access information, it is available at the click of a button (instead of recalling the information / data, one says, "let's Google it"). Undeniably, over-reliance on connected devices (digital devices connected to the internet) and the internet contribute to developing digital amnesia. These digital devices range from smartphones, palmtops, tablets, laptops, computers to all other digitally equipped technological devices; however, research on digital amnesia in general and this review shall often refer digital devices and smartphones interchangeably as smartphones are the most used digital devices. The symbiotic living with digital devices, as a result of the technological evolution, is changing the way we think, learn, behave, remember, live and evolve! 


\section{What does Kaspersky Laboratory reports tell us}

Kaspersky Lab, a cybersecurity firm in Moscow conducted a survey-based research in 2015 with the aid of Opinion Matters, to unravel how far the reliance on technology has come and the impact on peoples' daily lives. The study questioned over 6,000 consumers in Europe, across the UK, France, Germany, Italy, Spain and the Netherlands. The research findings reported a direct link between the availability of data at the click of a button and a failure to commit that data to memory. The research found that many people struggle to recall memories and simple information they entrust to their devices, including the phone numbers of partners and parents. Based on these findings Kaspersky Lab coined the term "Digital Amnesia" - the experience of forgetting information you trust a digital device to store and remember for you. Kaspersky Lab conducted the study (2015-2016) across Europe, India and the U.S.A [4].

The research conducted in Europe revealed some surprising statistics where people reported the following:

- Devices were being used as digital brains, to store information people needed to remember.

- $34 \%$ of European consumers admitted that their smartphone was their memory, as it contained almost everything they need to know or recall.

- $32 \%$ of people admitted their digital devices are like an extension of their brain.

- Over three-quarters $(79 \%)$ of respondents were more reliant on their digital devices then for accessing information than they were five years ago.

- Digital amnesia was seen as a phenomenon in the old and young age groups.

The research conducted in the U.S.A. revealed -

- There was an overwhelming number of consumers who easily admitted their dependency on the Internet and devices as a tool for remembering.

- Almost all (91.2\%) of those surveyed agreed that they use the Internet as an online extension of their brain.

- Almost half (44.0\%) also admitted that their smartphone serves as their memory-everything they need to recall and want to have easy access to is all on it.

- In addition, many consumers were happy to forget, or risk forgetting information they could easily find, or find again online.

- When faced with a question, half of U.S. consumers would turn to the Internet before trying to remember and $28.9 \%$ would forget an online fact as soon as they had used it.

The research conducted in India delineated the following -

- $50 \%$ of the survey group treats the internet as an extension of their brain

- $73 \%$ of them use their smart phones to connect to the internet

- $50 \%$ of Indians aren't interested in remembering facts as much as they are interested in remembering the source for the facts

- The trend of smart phone dependency seems to decrease as the age of the test group increased. That's because smart phones have not been around for long enough to influence a 55-year-old man or woman the same way it's influencing a teenager.

\section{Is Digital Amnesia all bad?}

Findings across Europe, India and the U.S.A revealed the fact that very few people remembered the phone numbers when they were 15 , yet few remembered the phone number of their spouses or children. Statistically, 8 out of 10 people rely on their digital devices much more than they did 5 years ago. Reliance on digital devices is a convenient $\&$ reliable way of holding information to remember. Along with our behaviour, our brain is adapting too [5].

Apart from the above stated findings across the three geographical locations, it is also crucial to look at the following results -

1. In Europe, $64 \%$ of consumers using a connected device to 'remember' information meant that they could concentrate on something else instead. It is not always wrong with intentionally forgetting things that we know our devices can remember for us. There are so many things to remember, that an external memory-storage unit in such instances can be of great help. However, 
relying on devices to remember for us can be a problem if we need to remember the information directly or that information is important to us (for example- remembering a password).

Overreliance on digital devices can also be problematic if -

- Information is needed to be readily available when there is no access to digital storage or to a search engine.

- Information is crucial to remember since one cannot afford to rely only on a digital backup.

- Information is required to be internalized and remembered in the long-term.

2. Research also found that $58 \%$ of people did not antivirus to protect their information on the digital device, and only $29 \%$ people backed up the important information on their devices. More than $80 \%$ of people in general use accessories to make their digital devices look appealing however only $30 \%$ (approximately) invest to protect their information stored in the digital devices from any kind of malware, cyber-threat, theft, loss or virus invasion.

3. Kaspersky reports also discuss that digital amnesia is not just a millennial phenomenon but is and can be equally present (and sometimes more prevalent) in older age groups because the older age group may have more information to sort through. Depending on digital devices can help them offload some information to the device, which could further make recalling the retained information more easily. This is further evidenced by Kathryn Mills from UCL University of Cognitive Neurosciences who explains that dependence on digital devices is also the purpose behind some computing concepts like enterprise content management to big data- so that we can use information effectively than remember it. This delineation comes to the conclusion that there is a school of researchers who believe that remembering information is not as important as using information effectively [6].

4. Apart from adverse effects to the memory, newspaper reports have had mental health professionals sharing the incidence of behavioural problems like attention deficit, high irritability, aggression levels rising up. The presentation of depression, anxiety, panic attacks and posttraumatic stress disorder have also shown to have links with digital amnesia. Consequently, psycho-social variables like low self-esteem, low self-confidence and lack of self-identity also surface to concern. These behavioural and psychological signs emerged in individuals who either lost their smartphones which had a barrage of their personal and professional information; or their data was lost due to third-party malice [7].

5. There are theoretical linkages of digital amnesia with smartphone addiction. The distractions caused as a result of multi-tasking on smartphones is proposed as a reason for the inability of longterm memory formation and greater memory loss. It is further proposed that it interferes with the sleep patterns, causing interruptions. Interrupted sleep further reduces the ability for synaptic pruning to take place, thus, impairing the ability to retain new information and form new memories [8].

It is for us to further question whether freeing up space in our brain, by depending on digital devices, does it indeed make space for learning new skills and can it really lead to us to use our minds in newer ways? Research continue to strive for the answer while sifting the benefits of digital amnesia in the dearth of its limitations and adverse consequences.

\section{The 'how' of Digital Amnesia}

Psychologists have believed that stress can cause amnesia or affect the memory adversely. However, that is not the only reason, excessive use of mobile phones, can and does also lead to memory loss in humans.

The 'how' of digital amnesia can be explained like this- when an individual relies on the digital devices, every time one wants to look for information, they reach out to the smartphone. This quick-fix of looking up the internet for any information / data, reduces the burden on human memory systems. Thus, our working memory systems engage only in finding the source of information and the information referred to remains only in the short-term memory system. Because information is only a click away, we don't feel the need to remember it as it can quickly be looked up online and our digital devices can store that information for us. Such reliance on digital devices refrains us from learning a new-skill. Consequently, 
there is no information input to be rehearsed; when there is no rehearsal, there is quick decay of information; leading to nothing being stored in the long-term memory system. In conclusion, Maria Wimber, from the University of Birmingham, says that there seems to be a risk that the constant recording of information on digital devices makes us less likely to commit this information to long-term memory, and might even distract us from properly encoding an event as it happens" [9-11].

Another explanation also goes that when information is encoded and stored using lesser sensory inputs, the retention is likely to be poorer and weaker. Multisensory memories using the senses of sensation, vision, auditory and other senses help better store the same information as opposed digitally encoding it which in most cases using only the sense of vision (sometimes auditory).

\section{Can Digital Amnesia be prevented}

Whilst addressing the preventive aspect of digital amnesia, a quick check on the identification can be of great help. There are some questions that one can address, either to the self or another, in order to check if there has been a crawling effect of digital device usage on their memories:

- Where have you been storing your data- has it always been any of the digital devices?

- Have you been spending excessive time on digital media?

- Has your pattern of communication transformed to become only virtually?

- Have you been observing an adverse impact on your work- have you been experiencing forgetfulness, unfinished tasks, forgotten responsibilities?

- Are you unable to imagine a technology free zone?

- Do you feel amiss without your digital device?

Apart from maintain a mental health hygiene, some simple steps that one can undertake to keep the neurons firing and prevent digital amnesia are -

- Making a habit to memorise important information to you

- Making travel experiential, rather than clicking and snapping every moment on digital devices. Sometimes reminiscing the travel makes it more memorable

- You can still be where you want to, without a check-in

- Digital detox is essential, especially when done on a family level where the entire family practices spending digital free hours in order to motivate one another to inculcate the same.

- Safety of digital data should be maintained by investing into security for stored data rather than merely investing in the décor of the hardware.

- Bonding with nature is a good holistic practice to rejuvenate and detox.

\section{Conclusions}

Digital amnesia is a phenomenon under research and put in elementary understanding, it explains that what is not needed to be remembered, is easily forgotten. Cognitive neuroscientists and psychologists have not yet affirmed digital amnesia as a scientific phenomenon, but they agree that relying less on the mind, builds fewer neuron connections in the brain, stagnating its development. Among the restricted literature available, the disadvantages of digital amnesia overweigh the constricted advantage it possibly has. Given the lack of secure procedures to save the digitally stored information and the lurking threat of behavioural addiction, it is essential to realise the adversities of the growing phenomenon of digital amnesia.

\section{REFERENCES}

1. O'Gorman M. Taking care of digital dementia. C Theory 2015;18:2-18.

2. Copeland AJ, Barreau D. Helping people to manage and share their digital information: A role for public libraries. Library Trends 2011;59(4):637-49.

3. Sparrow B, Lui J, Wegner DM, Google effects on memory: cognitive consequences of having information at our fingertips. Science 2011;333(6043):776-8.

4. Kaspersky Lab. The rise and impact of Digital Amnesia. Retrieved from https://blog.kaspersky.com/files/2015/06/005-Kaspersky-Digital-Amnesia-19.6.15.pdf; 2015. 
5. Kaspersky Lab. Digital Amnesia at work, the risks and rewards of forgetting in business. http://newsroom.kaspersky.eu/fileadmin/user_upload/de/Downloads/PDFs/Digital_Amnesia_at_workthe_risks_and_rewards_of_forgetting_in_business.pdf; 2016.

6. Gwalani P. Excessive dependence on smart phones leading to digital amnesia: Survey. Times of India. Retrieved from, https://timesofindia.indiatimes.com/city/nagpur/excessive-dependence-on-smartphonesleading-to-digital-amnesia-survey/articleshow/48674669.cms; 2015.

7. Bhargava Y. Smart phone users face risk of digital amnesia. The Hindu. Retrieved from, https://www.thehindu.com/sci-tech/technology/gadgets/smartphone-users-face-risk-of-digitalamnesia/article7570248.ece; 2016

8. Coughlan S. Digital dependence 'eroding human memory'. BBC News. Retrieved from, https://www.bbc.com/news/education-34454264; 2015.

9. Kaspersky Lab Survey in India: Smartphone Addiction Cause Digital Amnesia. Retrieved from it-voice magazine and https://www.itvoice.in/index.php/it-voice-news/kaspersky-lab-survey-in-india-smartphoneaddiction-cause-digital-amnesia; 2015.

10. Wimber M, Alink A, Charest I, Kriegeskorte N, Anderson MC. Retrieval induces adaptive forgetting of competing memories via cortical pattern suppression. Nat Neurosci 2015;18(4):582-9.

$* * * * * * * * * * * * * * * * * * * * * * * * * * * * *$

Acknowledgements - Nil

Source of Funding - Nil

Conflict of Interest - Nil 